\title{
PERINGATAN JAM MALAM ANAK BERDASARKAN LOKASI HANDPHONE BERBASIS ANDROID
}

\author{
Andi Hutami Endang ${ }^{1}$, Marzuki $\mathbf{R}^{2}$ \\ 1,2 Jurusan Teknik Informatika UIN Alauddin Makassar \\ Jln. Sultan Alauddin 36 GOWA 92113 INDONESIA \\ ${ }^{1}$ hutami.endang@uin-alauddin.ac.id \\ $\underline{260200115068 @ \text { uin-alauddin.ac.id }}$
}

\begin{abstract}
Abstrak. Kecerdasan buatan atau Artificial Intelligence (AI), didefinisikan sebagai kecerdasan entitas ilmiah. Kecerdasan diciptakan dan dimasukkan ke dalam suatu mesin (komputer) agar dapat melakukan pekerjaan seperti yang dapat dilakukan oleh manusia. Beberapa macam bidang yang menggunakan kecerdasan buatan antara lain sistem pakar, permainan komputer (games), logika fuzzy, jaringan syaraf tiruan, dan robotika.
\end{abstract}

Android adalah sistem operasi dan platform pemrograman yang dikembangkan oleh Google untuk ponsel cerdas dan perangkat seluler lainnya (seperti table). Android bisa berjalan di beberapa macam perangkat dari banyak produsen yang berbeda. Android menyediakan kit development perangkat lunak untuk penulisan kode asli dan perakitan modul perangkat lunak untuk membuat aplikasi bagi pengguna Android. Android juga menyediakan pasar untuk mendistribusikan aplikasi. Secara keseluruhan, Android menyatakan ekosistem untuk aplikasi seluler.

Aplikasi ini memudah para orangtua untuk memantau anak - anak mereka, bila tidak sedang dirumah. Orangtua juga tidak perlu menyetel alarm secara terus menerus karena aplikasi ini menyetel alarm secara otomatis di jam 09.30.

\section{I.PENDAHULUAN}

A. Latar Belakang

Kecerdasan buatan atau Artificial Intelligence (AI), didefinisikan sebagai kecerdasan entitas ilmiah. Kecerdasan diciptakan dan dimasukkan ke dalam suatu mesin (komputer) agar dapat melakukan pekerjaan seperti yang dapat dilakukan oleh manusia. Beberapa macam bidang yang menggunakan kecerdasan buatan antara lain sistem pakar, permainan komputer (games), logika fuzzy, jaringan syaraf tiruan, dan robotika.

Walaupun AI memiliki konotasi ilmiah yang kuat, AI membentuk cabang yang sangat penting dalam bidang ilmu komputer, yang berhubungan dengan perilaku, pembelajaran dan adaptasi yang cerdas dalam sebuah mesin. Penelitian dalam AI menyangkut pembuatan mesin untuk mengotomatisasikan tugas - tugas yang membutuhkan perilaku cerdas. Termasuk contohnya adalah pengendalian, perancanaan dan penjadwalan, kemampuan untuk menjawab diagnose dan pertanyaan pelanggan, serta pengenalan tulisan tangan, suara dan wajah. Hal - hal seperti itu telah menjadi disiplin ilmu tersendiri, yang memusatkan perhatian pada penyediaan solusi masalah kehidupan nyata. Sistem AI sekarang ini sering digunakan dalam bidang ekonomi, obat - obatan, teknik dan militer, seperti yang telah dibangun dalam beberapa aplikasi perangkat lunak komputer rumah dan video game.

Secara garis besar, AI terbagi ke dalam dua paham pemikiran yaitu AI Konvensional dan Kecerdasan Komputasional (CI, Computational Intellegence). AI konvensional kebanyakan melibatkan metode - metode yang sekarang diklasifikasin sebagai pembelajaran mesin, yang ditandai dengan formalisme dan analisis statistik. Dikenal juga sebagai AI simbolis, AI logis, AI murni

dan AI cara lama (GOFAI, Good Old Fashioned Artificial Intelligence). Metode - metodenya meliputi :

1. Sistem pakar : menerapkan kapabilitas pertimbangan untuk mencapai kesimpulan. Sebuah sistem pakar dapat memproses sejumlah 
besar informasi yang telah diketahui dan menyediakan kesimpulan berdasarkan pada informasi tersebut.

2. Pertimbangan berdasar kasus.

3. Jaringan Bayesian.

4. AI bersar tingkah laku : metode modular pada pembentukan sistem AI secar manual.

Kecerdasan komputasional melibatkan pengembangan atau pembelajaran interatif, misalnya penalaan parameter seperti dalam sistem koneksionis. Pembelajaran ini berdasarkan pada data empiris dan diasosiakan dengan AI non - simbolis, AI yang tak teratur dan perhitungan lunak. Metode - metode pokoknya meliputi :

1. Jaringan Syaraf : sistem dengan kemampuan pengenalan pola yang sangat kuat.

2. Sistem Fuzzy : teknik - teknik untuk pertimbagan dibawah ketidakpastian, telah digunakan secara meluas dalam industri modern dan sistem kendali produk konsumen.

3. Komputasi Evolusioner : menerpkan konsep - konsep yang terinsprasi secara biologis seperti populasi, mutasi dan "survival of the fittest" untuk menghasilkan pemecahan masalah yang lebih baik.

\section{B.Rumusan Masalah}

Mengingatkan orangtua tentang jam malam seorang anak, berdasarkan hasil pengamatan kami masih banyak orang tua yang tidak peduli dengan jam malam seorang anak yang masih remaja. Karena anak yang memasuki usia ramaja rentan akan pergaulan yang bebas, dll. Disini kami membuat sebuah aplikasi berbasis android, dimana aplikasi ini mengingatkan orangtua tentang jam malam anak, ketika aplikasi ini di install maka secara otomatis akan mengingatkan jam malam yang telah kamu set pada jam 09.30 PM. Setelah peringatan menyala kita bisa membuka aplikasi ini untuk melihat lokasi anak anda.

\section{B. Batasan Masalah}

Batasan masalah yang akan kami bahas dalam karya tulis ini ada beberapa hal, yaitu :

1. Umur anak yang kami sasar untuk penggunaan aplikasi ini adalah anak yang memasuki usia remaja, kisaran umurnya yaitu, 12 sampai 17 tahun.
2. Aplikasi ini menyetel otomatis alarm pada pukul $09.30 \mathrm{pm}$.

\section{II.TINJAUAN PUSTAKA}

C. Komputer

Istilah komputer berasal dari kata compute, yang berarti menghitung. Artinya, setiap proses yang dilaksanakan oleh komputer merupakan proses matematika hitungan. Jadi, segala sesuatu yang dilakukan oleh komputer, baik yang ditampilkan pada layar monitor, suara, gambar, dan lain - lain diolah sedemikian rupa dari perhitungan secara elektronik.

Komputer berfungsi sebagai alat bantu untuk menulis, menggambar, menyunting gambar, atau foto, membuat animasi, mengoperasikan program analisi ilmiah, simulasi, untuk kontrol peralatan. Awalnya, komputer merupakan peralatan yang mahal dan berukuran besar. Akhirnya, muncullah suatu komputer yang lebih kecil dan dirancang untuk digunakan oleh satu user dengan kemampuan untuk mengoperasikan program yang beragam. Komputer seperti ini disebut Personal Computer atau disingkat dengan PC. Akhir - akhir ini telah diciptakan pula mobile PC yang sering dikenal dengan notebook atau laptop. Komputer ini mudah dibawah dan dipindahkan (mobile).

Di era perdagangan bebas, personal computer (PC) juga dikembangkan dengan standar terbuka sehingga banyak sekali perusahaan yang membuat perangkat kerasnya. Setiap jenis perangkat keras bisa dibuat oleh perusahaan yang berbeda, namun perangkat keras tersebut tetap masih bisa dipakai.

Komponen - komponen perangkat pendukung sebuah personal computer terdiri dari beberapa pendukung - pendukung utama sebagai berikut.

1. Monitor

Monitor merupakan layar yang digunakan untuk menampilkan program dan data yang sedang diproses.

2. Keyboard

Keyboard merupakan papan ketik yang berguna untuk member perintah pada komputer.

3. Mouse

Mouse merupakan sebuah peralatan yang digunakan sebagai ponting device yaitu untuk mengklik menu atau tombol yang ditampilkan dalam layar.

4. $\mathrm{CPU}$ 
CPU merupakan otak dari komputer, disinilah semua perintah dip roses.

\section{Android}

Android adalah sistem operasi dan platform pemrograman yang dikembangkan oleh Google untuk ponsel cerdas dan perangkat seluler lainnya (seperti table). Android bisa berjalan di beberapa macam perangkat dari banyak produsen yang berbeda. Android menyediakan kit development perangkat lunak untuk penulisan kode asli dan perakitan modul perangkat lunak untuk membuat aplikasi bagi pengguna Android. Android juga menyediakan pasar untuk mendistribusikan aplikasi. Secara keseluruhan, Android menyatakan ekosistem untuk aplikasi seluler.

Android menyediakan antarmuka pengguna (UI) layar sentuh untuk berinteraksi dengan aplikasi. Antarmuka pengguna Android sebagian besar berdasarkan pada manipulasi langsung, menggunakan isyarakat sentuhan seperti menggesek, mengetuk, dan mencubit untuk memanipulasi objek di layar. Selain keyboard, ada keyboard virtual yang bisa disesuaikan untuk masukan teks. Android juga bisa mendukung pengontrol game dan keyboard fisik berukuran penuh yang dihubungkan dengan Bluetooth atau USB.

Layar utama Android bisa berisi sejumlah laman ikon aplikasi, yang akan meluncurkan aplikasi terkait, dan widget, dengan menampilkan materi langsung yang diperbarui secara otomatis seperti cuaca, kotak masuk email pengguna, atau ticker berita. Android juga bisa memutar materi multimedia seperti musik, animasi, dan video. Android didesain untuk menyediakan respons cepat terhadap masukan pengguna. Selain antarmuka sentuh yang berubah ubah, kamampuan getaran perangkat Android bisa menyediakan umpan balik sentuhan. Perangkat keras internal seperti akselerometer, giroskop, dan sensor kedekatan, digunakan oleh banyak aplikasi untuk merespons tindakan pengguna tambahan. Sensor tersebut bisa mendeteksi rotasi layar dari potret ke lanskap untuk tampilah yang lebih lebar atau sensor bisa memungkinkan pengguna untuk menyetir kendaraan virtual dengan memutar perangkat seolah - olah setir mobil.

Platform Android, berdasarkan karnel linux, terutama didesain untuk perangkat seluler layar sentuh seperti ponsel cerdas dan tablet. Karena perangkat Android biasanya bertenaga baterai, Android didesain untuk mengelola proses guna menjaga konsumsi daya tetap minimum, sehingga menyediakan penggunaan baterai lebih lama.

E. Handphone

Handphone adalah perangkat telekomunikasi elektronik yang mempunyai kemampuan dasar yang sama dengan telepon konvensional saluran. Namun dapat dibawah kemana - mana dan tidak perlu disambungkan dengan jaringan telepon menggunakan kabel. Saati ini, Indonesia mempunyai dua jaringan telepon nirkabel yaitu sistem GSM (Global System for Mobile Telecommunications) dan sistem CDMA (Code Division Multiple Access). Badan yang mengatur telekomunikasi seluler Indonesia adalah Asosiasi Telekomunikasi Seluler Indonesia (ATSI).

Penemu telpon ganggam yang pertama adalah Martin Cooper, seorang karyawan Motorola pada tanggal 03 April 1973, walaupun banyak disebut - sebut penemu telepon ganggam adalah sebuah tim dari salah satu divisi Motorola (divisi tempat Cooper bekerja) dengan model pertama adalah DynaTAC. Ide yang dicetuskan oleh Cooper adalah sebuah alat komunikasi yang kecil dan mudah dibawa bepergian secara fleksibel.

Cooper bersama timnya menghadapi tantangan bagaimana memasukkan semua material elektronik ke dalam alat yang berukuran kecil tersebut untuk pertama kalinya. Namun akhirnya sebuah telepon genggam pertama berhasil diselesaikan dengan total bobot seberat dua kilogram. Untuk memproduksinya, Motorola membutuhkan biaya setara dengan US\$1 juta. "Pada tahun 1993, telepon genggam portabel berharga US\$4 ribu (Rp. 36 juta) setara dengan US\$10 ribu (Rp. 90 juta).

Setelah berhasil memproduksi telepon genggam, tantangan terbesar berikutnya adalah mengadaptasi infrastruktur untuk mendukung sistem komunikasi telepon genggam tersebut dengan menciptakan sistem jaringan yang hanya membutuhkan $3 \mathrm{MHz}$ spektrum. Setara dengan lima channel TV yang tersalur keseluruh dunia.

\section{F. Bahasa Pemrograman Java}

Java adalah bahasa pemrograman tingkat tinggi yang berorientasi objek dan program java tersusun dari bagian yang disebut kelas. Kelas terdiri atas metode - metode yang melakukan pekerjaan dan mengembalikan informasi setelah melakukan tugasnya. Beberapa keunggulan java yaitu, java merupakan bahasa yang sederhana. Java dirancang agar mudah dipelajari dan digunakan secara efektif, 
java tidak menyediakan fitur - fitur rumit bahasa pemrograman tingkat tinggi, serta banyak pekerjaan pemrograman yang mulanya harus dilakukan manual, sekarang digantikan oleh java yang mengerjakannya secara otomatis seperti dealokasi memori.

Java menggunakan model pengamanan tiga lapis (three-layer security model) untuk melindungi sistem dari untrusted java code. Pertama bytecode verifier membaca bytecode sebelum dijalankan dan menjamin bytecode memenuhi aturan - aturan dasar bahasa java. Kedua class loader menangani pemuatan kelas java ke runtime interpreter. Ketiga manajer keamanan menangani keamanan tingkat aplikasi dengan mengendalikan apakah program berhak mengakses sumber daya seperti sistem file, port jaringan, proses eksternal dan sistem windows.

\section{G. Android Studio}

Android Studio adalah lingkungan pengembangan terpadu - Integrated Development Environment (IDE) untuk mengembangkan aplikasi Android, berdasarkan IntelliJ IDEA. Selain merupakan editor kode IntelliJ dan alat pengembang yang berdaya guna, Android Studio menawarkan fitur lebih banyak untuk meningkatkan produktivitas anda saat membuat aplikasi Android, misalnya :

1. Sistem versi berbasis Gradle yang fleksibel.

2. Emulator yang cepat dan kaya fitur.

3. Lingkungan yang menyatu untuk mengembangkan bagi semua perangkat android.

4. Instant Run untuk mendorong perubahan ke aplikasi yang berjalan tanpa membuat APK baru.

5. Tamplate kode dan integritas GitHub untuk membuat fitur aplikasi yang sama dan mengimpor kode contoh.

6. Alat pengujian dan kerangka kerja yang ekstensif.

7. Alat Lint untuk meningkatkan kinerja, kegunaan, kompatibilitas versi, dan masalah - masalah lain.

8. Dukungan $\mathrm{C}++$ dan NDK.

9. Dukungan bawaan untuk Google Cloud Platform, mempermudah pengintegrasian Google Cloud Messaging dan App Engine.

H. Emulator

Android Emulator menyimulasikan sebuah perangkat dan menampilkannya pada kumputer anda. Itu memungkinkan anda membuat prototype, mengembangkan, dan menguji aplikasi Android tanpa menggunakan perangkat keras. Emulator mendukung ponsel Android, tablet, Android Wear, dan perangkar Android TV. Dilengkapi dengan tipe perangkat yang telah ditentukan sehingga anda bisa memulai dengan cepat, dan dapat menentukan perangkat dan skin emulator anda sendiri.

Android Emulator memiliki banyak fitur, cepat, dan kuat. Itu bisa mentransfer informasi lebih cepat dibandingkan dengan menggunakan perangkat keras yang tersambung, mempercepat proses pengembangan. Fitur multi-core memungkinkan emulator untuk memanfaatkan prosesor muti-core pada komputer pengembangan untuk semakin meningkatkan kinerja emulator.

\section{METODE PENELITIAN}

I. Alat dan Bahan

Alat dan bahan yang saya gunakan dalam membuat aplikasi ini, sebagai berikut :

1. Komputer / laptop

Spesifikasi :
a. Prosesor
: AMD A10-7300 RadeoR6
b. RAM
: $6 \mathrm{~GB}$
c. VGA
: $2 \mathrm{~GB}-3 \mathrm{~GB}$
d. Hardisk
$: 1 \mathrm{~TB}$
e. DirectX Version : DirectX 12

2. Android Studio

System Requirement Android Studio di Windows :
a. OS
: Windows $7 / 832-6$ bit
b. RAM
: 4 GB (disarankan 8GB)
c. Ruang Hardisk : 2 GB (disarankan 4GB)
d. Resolusi Layar : $1280 \times 800$
e. Java Development Kit (JDK) 7

3. MEmu Android

System Requirement Android Studio di Windows
a. OS
: Windows $7 / 832-6$ bit
b. RAM
$: 2 \mathrm{~GB}$
c. Ruang Hardisk
: 5 GB
d. Prosesor
: Intel / AMD

\section{Handphone}

System Requirement :
a. OS
Android Lollipop 5.0

\section{J. Cara Kerja}


Disini kami menuliskan kode - kode di Android

Studio atau biasa disebut coding. Sampai menjadi sebuah aplikasi.

\section{K. Analisis Data}

Dalam penilitian ini kami menggunakan Metode Wawancara.

1. Metode Wawancara

Wawancara adalah proses memperoleh keterangan untuk tujuan penelitian dengan cara Tanya jawab sambil bertatap muka antara si peneliti dengan objek penelitian. Keterangan keterangan yang hendak diperoleh melalui wawancara biasanya adalah keterangan dalam memperoleh dan memastikan fakta, memperkuat kepercayaan, memperkuat perasaan, mengenali standar kegiatan, dan untuk mengetahui alasan seseorang.

a. Keuntungan dan Kelemahan Metode Wawancara

Keuntungan :

i. Salah satu teknik terbaik untuk mendapatkan data pribadi.

ii. Tidak terbatas pada tingkat pendidikan tertentu, asalkan responden dapat berbicara dengan baik.

iii. Dapat dijadikan pelengkap teknik pengumpulan data lainnya.

iv. Sebagai penguji terhadap data yang didapat dengan teknik pengumpulan lainnya.

Kelemahan :

i. Responden harus mampu bicara dengan jelas dan benar.

ii. Waktu, biaya, dan tenaga yang digunakan tidak efisien . iii. Sangat tergantung pada kesediaan responden.

iv. Proses wawancara sangat mudah dipengaruhi oleh keadaan yang terjadi pada saat wawancara.

v. Untuk objek yang luas, diperlukan pewawancara yang banyak jumlahnya.

\section{HASIL DAN PEMBAHASAN}

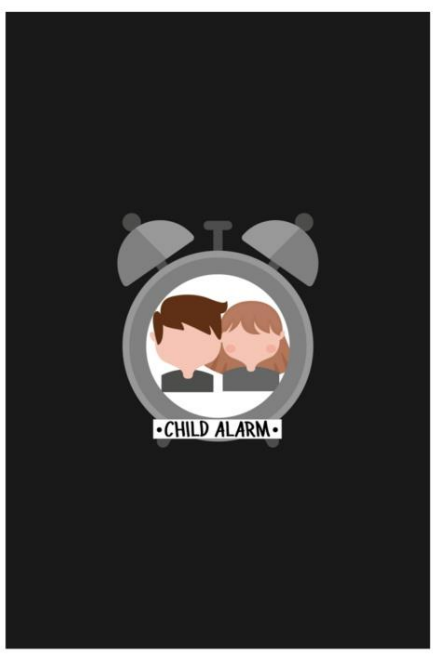

Gambar 1. Tampilan awal
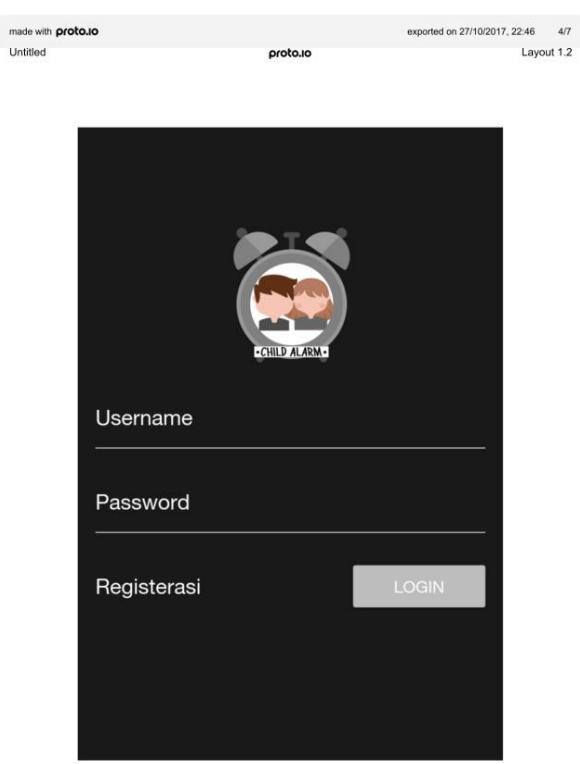

Gambar 2. User Login

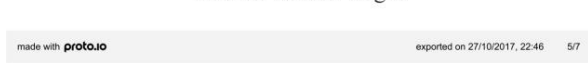



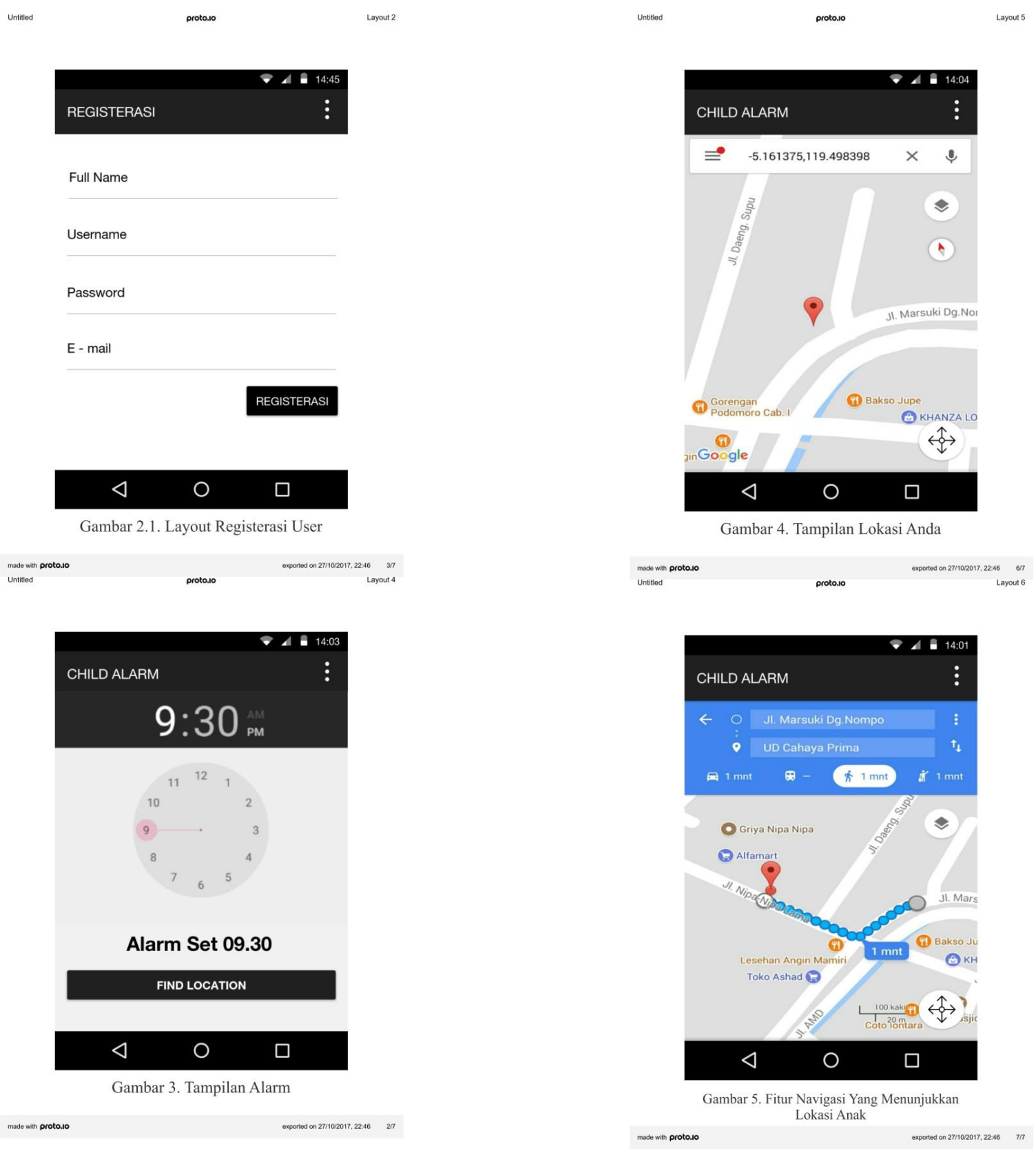

Algoritma dari aplikasi ini :

1. Melakukan registerasi untuk login.

2. Login sesuai dengan username dan password akun yang telah dibuat.

3. Alarm otomatis di set pada jam 09.30.

4. Fitur "Find Location" untuk melihat lokasi anda.

5. Fitur "Navigasi" untuk menentukan jalan ke lokasi anak anda. 
Alarm dari aplikasi ini otomatis aktif jika

koordinat GPS Handphone anak anda tidak ada di

lokasi yang sudah anda tentukan.

\section{IV.KESIMPULAN DAN SARAN}

A. Kesimpulan

Kecerdasan buatan atau Artificial Intelligence (AI), didefinisikan sebagai kecerdasan entitas ilmiah. Kecerdasan diciptakan dan dimasukkan ke dalam suatu mesin (komputer) agar dapat melakukan pekerjaan seperti yang dapat dilakukan oleh manusia.

Aplikasi ini memudah para orangtua untuk memantau anak - anak mereka, bila tidak sedang dirumah. Orangtua juga tidak perlu menyetel alarm secara terus menerus karena aplikasi ini menyetel alarm secara otomatis di jam 09.30.

B. Saran

1. Penelitian ini masih jauh dari kata sempurna, untuk pengembangan aplikasi dapat menggunakan beberapa metode Artificial Intelligence (AI).

2. Penelitian ini dapat dikembangkan lebih lanjut untuk dengan menambahkan beberapa fitur pada aplikasi.

\section{DAFTAR PUSTAKA}

[1] Training Team.2016. Google Developer. Android Developexr Fundamentals Course : Learn to Develop Android Applications.

[2] Eko Supriyadi, Muslim Heri Kiswanto.2010. editor, Muh. Irwansyah; illustrator,Heri Parwoko.-Jakarta: Pusat Perbukuan, Kementerian Pendidikan Nasional,CV Sinar Mandiri.

[3] https://id.wikipedia.org/wiki/Kecerdasan_buatan -- diakses pada tanggal 13 oktober 201

[4] https://id.wikipedia.org/wiki/Telepon_genggam\#Sejarah -- diakses pada tanggal 18 oktober 2017

[5] https://developer.android.com/studio/intro/index.html?hl=id -- diakses pada tanggal 4 November 2017

[6] https://developer.android.com/studio/run/emulator.html?hl=id diakses pada tanggal 4 November 2017

[7] http://www.perpusku.com/2016/06/metode-pengumpulan-data-denganmetode-wawancara-interview.html $\quad--$ diakses pada tanggal 4 November 2017 